\title{
Getting into Learners' Pace: Teacher-Made Brochures in Gen-Math and Stat
}

Elymar A. Pascual

Department of Education, Nagcarlan, Laguna, Philippines, 4002

elymarpascual@rocketmail.com

\begin{abstract}
This study focused on determining the effectiveness of the use of teacher-made brochures in GenMath and Stat-and-Prob subjects of Grade 11 learners in Talangan Integrated National High School, Nagcarlan, Laguna, Philippines. The researcher developed 100 teacher-made brochures and used them in classes. The experimental method of research was followed. The ABM-GAS section composed of 26 learners was divided into three groups (A, B, C). For three weeks, all the groups had their turn to be the controlled (no brochures were given), experimental 1 (brochures were given on the day of discussion), and experimental 2 (brochure were given a week before the discussion). Each week has three lessons with a 10-item quiz provided at the end of each session. Explanatory sequential mixed method was applied, i.e., after the gathering, encoding, statistical treatment, and analysis, a survey on the benefit of using brochures was conducted. It was found out that using brochure, the controlled had a mean level of 6.22, experimental 1 gained 7.01, while experimental 2 obtained 8.13. The difference was found to be significant using ANOVA, proven by p-value 0.000 (alpha 0.05). Providing brochures to learners beforehand results into significantly high scores in quizzes. From the survey, the benefits for learners are: (1) facility in taking down lecture notes (2) preparation for classroom discussion, (3) easy comprehension of the lesson, (4) motivation for learning, (5) material for enhancement of skill, (6) serves as review material, and (7) increased academic performance. For Math teachers, the following were highlighted: (1) facility on teaching, (2) lecture adaptation to interest and capability of learners, (3) reduction of stress, (4) teacher fulfillment, and (5) contingency material for teacher's unavailability. Recommendations to math teachers, coordinators, school heads, education program specialists, and future researchers were given at the end of the study.
\end{abstract}

Key words: brochure, learner, math, teacher, statistics

\section{Introduction/Background}

Instructional materials took the form of simple art paper, manipulatives, natural objects in the surroundings, digital materials like video clips, powerpoint and net sources. Teacher can be innovative in the production and use of instructional materials. There are many available ready-made which the Department of Educational not only promote the use but also monitors the singing-up and utilization of those available in the government sites like LRM portal. Many have explored on the benefit that can be gained from using and reusing those materials, and even the modification of those done by authorities.

Getting into the concept of localization and contextualization of the curriculum, teachers are given the challenge of personalizing and doing their own instructional materials to be used in the classroom setting with the given culture of the community where the school is.

This is the very reason why this action research has come into mind. The production of teacher-made brochure which is summarized and crafted for daily classroom setting is to be investigated as to its effectiveness in increasing academic performance. Would handling these brochures aid in better understanding of Math concepts? Which way of handling the material be more beneficial to learners, handling it to them beforehand or handling it to them on the day of classroom session? What to learners, parents and other Math teachers think about the production of teacher-made brochures for classroom use, and even for modular purposes? Those are some of the things that this paper would explore.

\subsection{Statement of the Problem}

The main focus of this action research is to find out the effectiveness of the use teacher-made instructional materials in attaining higher academic performance. 
Specifically, it seeks to answer the following questions:

1. What is the mean level of academic performance of the following group of learners on the first week of teaching:

a. Group A (controlled, math brochure not given)

b. Group B (experimental 1, math brochure given on the session day)

c. Group C (experimental 2, math brochure given beforehand)?

2. What is the mean level of academic performance of the following group of learners on the second week of teaching:

a. Group A (experimental 1, math brochure given on the session day)

b. Group B (experimental 2, math brochure given beforehand)

c. Group $\mathrm{C}$ (controlled, math brochure not given)?

3. What is the mean level of academic performance of the following group of learners on the third week of teaching:

a. Group A (experimental 2, math brochure given beforehand)

b. Group B (controlled, math brochure not given)

c. Group C (experimental 1, math brochure given on the session day)?

4. What is the mean level of academic performance of learners for three weeks under the three scenarios:

a. controlled (math brochure not given);

b. experimental 1 (math brochure given on the session day);

c. experimental 2 (math brochure given beforehand);

5. Is there a significant difference in academic performance of the following scenarios:

a. Three groups during the first week of teaching;

b. Three groups during the second week of teaching;

c. Three groups during the third week of teaching;

d. Three scenarios for the three weeks of teaching; and

6. What are the benefits of using teacher-made brochures to learners and to math teachers?

\section{Review of Related Literature}

According to findings in the study made by Adipo (2015), it can be seen that the control group of schools had mean and standard deviation of 52.70 and 13.57, respectively, while the experimental group of schools had a mean and standard deviation of 74.30 and 8.74 , respectively. The difference in performance of children in control group of schools and those in experimental group of schools was found to be statistically significant ( $\mathrm{t}(8)=-5.482, \mathrm{p}=.004$, two tailed). This suggests that children who are taught mathematics using instructional materials perform better than those who are only taught mathematics using abstract mathematics symbols only. The difference in performance is due to interventions (treatment) done to the experimental group of schools.

According to Aduwa Et Al, (2005), these materials and resources include, audio tapes recorders, video tape recorders, slide projectors, still pictures, programmed instructional film strips, maps, chart, graphs and many more; offer a variety of learning experience individually or in combination to meet different teaching and learning experiences.

The "term mathematical instructional resource" is defined as any form of specific mathematical apparatus (Structured or unstructured), image, ICT game, tool, paper, or everyday material which could be utilized to provide a mathematical teaching or learning (Doreen, Et. Al, 2007).

Onasanya et al: (2008) noted that improvisation demands adventure, creativity, curiosity and perseverance on the part of teachers.

Ikwuas and Onwiodiket (2006) state that improvised materials involve selection and deployment of relevant instructional elements of teaching and learning processes in absence or shortage of standard teaching and learning materials, for meaningful realization of specified educational goals and objectives. 
Abimbade (2004) had earlier noted that the approach of using improvised materials in mathematics classroom assist in proper introduction of new skills, develop understanding as well as show the appropriate way of doing things.

Orji (2012) in his study found out that instructional materials are not necessarily important if the learners are intelligent and the teacher has good mastery of the subject matter.

Egbu (2012) argued that involving learners in classroom activities is what matters most as it makes teaching learner centered.

In accordance with the findings in the study made by Koparan (2017), it is concluded that prospective teachers have positive views and attitudes to general teaching technologies and materials development. Pretests and posttests were administered to the respondents before and after the use of IMs to ascertain the changes in students' performance, and Mathematics self-efficacy beliefs in terms of attitude towards Mathematics, Mathematics anxiety and motivation to do Mathematics. The three Ims in grade 7 Mathematics, High School Statistics and Method of Research were found effective in enhancing student learning.

Bolick and others (2003) pointed to a good relationship between effective teaching and use of instructional materials. He argued that even if there are some educators who found the potential of IM's in enhancing teaching and learning, most of them are behind in utilizing these materials during instruction, while others expressed doubts that these will ever provoke teaching reform.

Ogbondah (2008), stressed that the need to develop an effective instructional system is both an opportunity and a threat. It is a challenge at the same time, an opportunity to educate teachers and learning experiences based on a carefully planned learning experience.

Tahir (2002) admitted that there is general lack of Ims that match the teaching styles of teachers and learning styles of students.

\section{Research Design and Methodology}

\subsection{Research Design}

The study made use of the experimental design in doing research. Montgomery (1997) defines an experimental design as the process of planning a study to meet specified objectives and experiment as a process or study that result in the collection of data where the results of the experiment are not known in advance. The class/respondents in this study were divided into three groups: control group, experimental group with brochure given on the day of session, and experimental group with brochure given beforehand. Teaching sessions were conducted and quizzes will be given. For three weeks, groups rotated as to the manner of having the brochure, each group having their turn of experiencing being the control and experimental groups. Results were recorded and analyzed as to the effectiveness of the brochure. Explanatory sequential mixed method followed in analyzing the responses to written interview to learners and teachers with regards to the benefits in using brochures in classroom sessions. 
3.2. Data Gathering Procedure

This flowchart highlights steps undertaken in conducting this action research.

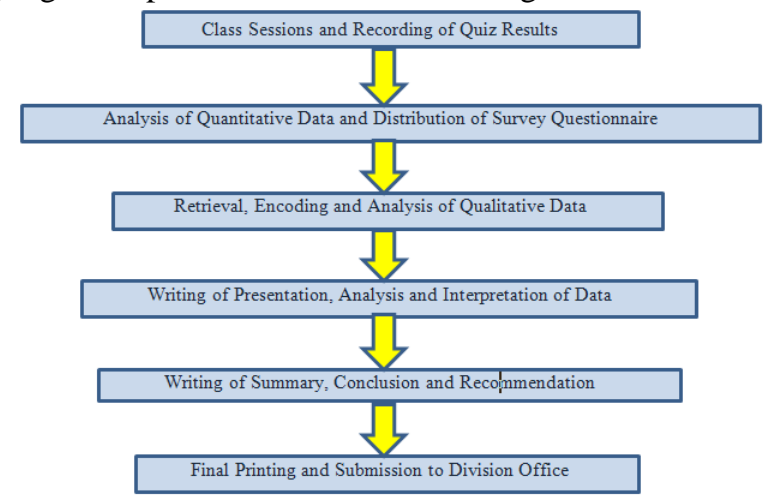

Figure 1. Flowchart of Research Procedure

\subsection{Research Respondents}

The class/respondent that will be used to gather data will be the ABM/GAS 11 Vibrant of Talangan Integrated National High School. This section is composed of 20 ABM and 6 GAS learners, having a total of 26 learners. The division into three groups will be done in this manner:

Table 1. Frequency of Research Respondents

\begin{tabular}{|l|c|c|c|}
\hline \multicolumn{1}{|c|}{ Set-up } & ABM & GAS & Total \\
\hline Control & 7 & 2 & 9 \\
\hline $\begin{array}{l}\text { Experimental } \\
\text { (brochure given on the } \\
\text { day of session) }\end{array}$ & 7 & 2 & 9 \\
\hline $\begin{array}{l}\text { Experimental given } \\
\text { (brochure } \\
\text { beforehand }\end{array}$ & 6 & 2 & 8 \\
\hline Total & & & \\
\hline
\end{tabular}

The table presented above will be the frequency for the three-week classroom sessions, except for the groupings which will rotate. For the second week, the control group will be the experimental group 1, and the experimental group 1 will be the group 2, while the experimental group 2 will be the control group. This way of rotation will be applied for the third week, making all groups pass through all the scenarios of having or not having the teacher-made brochure.

\subsection{Data Collection}

Both quantitative and qualitative data will be used in generating in answers to questions posted at the beginning of the study. For the quantitative data, formative quizzes scores will be recorded each session which will be done three to four times a week. For three weeks, there will be nine to twelve quizzes. The scores will be analyzed so as to verify the effectiveness of the use of teacher-made brochure. For the qualitative data, response to survey questions on effectiveness of teacher-made brochure will be sorted, analyzed and interpreted. 
3.5. Statistical Tools

The statistical tools that would aid in answering the specific questions at the beginning of the study are listed below:

$$
\begin{aligned}
& \text { SOP \#1 - mean and standard deviation } \\
& \text { SOP \#2 - mean and standard deviation } \\
& \text { SOP \#3 - mean and standard deviation } \\
& \text { SOP \#4 - mean and standard deviation } \\
& \text { SOP \#5 - analysis of variance (ANOVA) } \\
& \text { SOP \#6 - frequency and percentage }
\end{aligned}
$$

\section{Presentation, Analiysis and Interpretation of Data}

4.1. Academic Performance on the First Teaching Sessions

Table 2. Mean Level of Academic Performance, First Week

\begin{tabular}{|l|c|c|c|}
\hline \multicolumn{1}{|c|}{ Groups } & Mean & SD & Interpretation \\
\hline $\begin{array}{l}\text { Group A (controlled, } \\
\text { math brochure not given) }\end{array}$ & 6.96 & 0.85 & Approaching Proficiency \\
\hline $\begin{array}{l}\text { Group B (experimental 1, } \\
\text { math brochure given on } \\
\text { the session day) }\end{array}$ & 7.22 & 1.41 & Advanced \\
\hline $\begin{array}{l}\text { Group C (experimental 2, } \\
\text { math brochure given } \\
\text { beforehand) }\end{array}$ & 8.52 & 1.99 & \\
\hline
\end{tabular}

Legend:

$\begin{array}{ll}8.00-10.00 & \text { Advanced } \\ 7.00-7.99 & \text { Proficient } \\ 6.00-6.99 & \text { Approaching Proficiency } \\ 5.00-5.99 & \text { Developing } \\ \text { below } 5.00 & \text { Beginning }\end{array}$

The table above shows the result of the first week teaching sessions in Statistics and Probability. Three quizzes of 10 items each were given for the entire week. Results were recorded and treated statistically. Mean of 6.96 was obtained by Group A learners who did not receive teacher-made brochures, 7.22 for Group $\mathrm{B}$ (received brochure during the discussion), and 8.52 for Group $\mathrm{C}$ (received brochure one week before the session). The standard deviations were $0.84,1.99$ and 1.41 respectively. Group A is seen to be homogenous group, while Groups B and C are heterogenous in terms of their scores in the three quizzes given. When brochures are given in advance, learners get the highest score, compared to the group who did not receive or received brochure only on the day discussion.

4.2. Academic Performance on the Second Teaching Sessions

Table 3. Mean Level of Academic Performance, Second Week

\begin{tabular}{|l|c|c|c|}
\hline \multicolumn{1}{|c|}{ Groups } & Mean & SD & Interpretation \\
\hline $\begin{array}{l}\text { Group A (experimental } \\
\text { 1, math brochure given } \\
\text { on the session day) }\end{array}$ & 6.17 & 0.40 & Approaching Proficiency \\
\hline Group B (experimental 2, & 7.15 & 1.28 & Proficient \\
\hline
\end{tabular}




\begin{tabular}{|l|c|c|c|}
\hline $\begin{array}{l}\text { math brochure given } \\
\text { beforehand) }\end{array}$ & & \\
\hline $\begin{array}{l}\text { Group C (controlled, } \\
\text { math brochure not given) }\end{array}$ & 5.11 & 0.80 & Developing \\
\hline
\end{tabular}

Legend:

$\begin{array}{ll}8.00-10.00 & \text { Advanced } \\ 7.00-7.99 & \text { Proficient } \\ 6.00-6.99 & \text { Approaching Proficiency } \\ 5.00-5.99 & \text { Developing } \\ \text { below } 5.00 & \text { Beginning }\end{array}$

The table above shows the result of the second week teaching sessions in Statistics and Probability. Three quizzes of 10 items each were given for the entire week. Results were recorded and treated statistically. Mean of 7.15 was obtained by Group A learners who received the brochures a week before the discussion, 5.11 for Group B (did not receive the brochures), and 6.17 for Group C (received brochures on the day of the discussion). The standard deviations were 1.28, 0.80 and 0.40 respectively. Groups B and C are seen to be homogenous groups, while Group A is heterogenous in terms of their scores in the three quizzes given. When brochures are given in advance, learners get the highest score, compared to the group who did not receive or received brochure only on the day discussion.

\subsection{Academic Performance on the Third Teaching Sessions}

Table 4. Mean Level of Academic Performance, Third Week

\begin{tabular}{|l|c|c|c|}
\hline \multicolumn{1}{|c|}{ Groups } & Mean & SD & Interpretation \\
\hline $\begin{array}{l}\text { Group A (experimental } \\
\text { 2, math brochure given } \\
\text { beforehand) }\end{array}$ & 8.79 & 1.25 & Advanced \\
\hline $\begin{array}{l}\text { Group B (controlled, } \\
\text { math brochure not given) }\end{array}$ & 6.67 & 1.47 & Approaching Proficiency \\
\hline $\begin{array}{l}\text { Group C (experimental 1, } \\
\text { math brochure given on } \\
\text { the session day) }\end{array}$ & 7.56 & 1.05 & Proficient \\
\hline
\end{tabular}

Legend:

$\begin{array}{ll}8.00-10.00 & \text { Advanced } \\ 7.00-7.99 & \text { Proficient } \\ 6.00-6.99 & \text { Approaching Proficiency } \\ 5.00-5.99 & \text { Developing } \\ \text { below } 5.00 & \text { Beginning }\end{array}$

The table above shows the result of the third week teaching sessions in Statistics and Probability. Three quizzes of 10 items each were given for the entire week. Results were recorded and treated statistically. Mean of 7.56 was obtained by Group A learners who received the brochures on the day of the discussion, 8.79 for Group B (received brochures one week before the discussion), and 6.67 for Group C (did not receive brochures). The standard deviations were 1.05, 1.25 and 1.47 respectively. All groups are seen to be heterogenous in terms of their scores in the three quizzes given. When brochures are given in advance, learners get the highest score, compared to the group who did not receive or received brochure only on the day discussion. 
4.4. Academic Performance of the Three Groups

Table 5. Mean Level of Academic Performance of Three Groups

\begin{tabular}{|l|c|c|c|}
\hline \multicolumn{1}{|c|}{ Set-up } & Mean & SD & Interpretation \\
\hline $\begin{array}{l}\text { Controlled, math } \\
\text { brochure not given }\end{array}$ & 6.22 & 1.34 & Approaching Proficiency \\
\hline $\begin{array}{l}\text { Experimental 1, math } \\
\text { brochure given on the } \\
\text { session day }\end{array}$ & 7.01 & 1.18 & Proficient \\
\hline $\begin{array}{l}\text { Experimental 2, math } \\
\text { brochure given } \\
\text { beforehand }\end{array}$ & 8.13 & 1.67 & Advanced \\
\hline
\end{tabular}

Legend:

$\begin{array}{ll}8.00-10.00 & \text { Advanced } \\ 7.00-7.99 & \text { Proficient } \\ 6.00-6.99 & \text { Approaching Proficiency } \\ 5.00-5.99 & \text { Developing } \\ \text { below } 5.00 & \text { Beginning }\end{array}$

The table above shows the result of the three-week teaching sessions in Statistics and Probability. Nine quizzes of 10 items each were given for the entire three weeks. Results were recorded and treated statistically. Mean of 6.22 was obtained when learners do not receive teacher-made brochures, 7.01 when learners receive brochures during discussion time, and 8.13 when learners receive brochures one week before discussion time. The standard deviations were 1.34, 1.18 and 1.67 respectively. All groups are seen to be heterogenous in terms of their scores in the three quizzes given. Same as the individual weeks' analysis, the combination of three weeks observation speaks, i.e., when brochures are given in advance, learners get the highest score, compared to the group who did not receive or received brochure only on the day discussion.

\subsection{Difference in Academic Performance of the Three Groups}

Table 6. ANOVA Result of the Three Groups (Controlled Group, Experimental Group 1 and Experimental Group 3)

\begin{tabular}{|c|c|c|c|c|}
\hline Sessions & F-value & F-crit & P-value & Decision \\
\hline $\begin{array}{c}\text { First Session } \\
\text { (Week 1) }\end{array}$ & 2.657 & 3.422 & 0.092 & Not Significant \\
\hline $\begin{array}{c}\text { Second Session } \\
\text { (Week 2) }\end{array}$ & 11.089 & 3.422 & 0.000 & Significant \\
\hline $\begin{array}{c}\text { Third Session } \\
\text { (Week 3) }\end{array}$ & 5.947 & 3.422 & 0.008 & Significant \\
\hline Overall (3 Weeks) & 12.068 & 3.119 & 0.000 & \\
\hline
\end{tabular}

alpha $=0.05$

The table above shows the ANOVA result of the significant difference of mean scores of the three scenarios regarding handling or receiving brochures - control (not receiving brochures), experimental 1 (receiving brochures on the day of the discussion) and experimental 2 (receiving brochures a week before the discussion). On the first week, the mean scores of the three groups are not significantly different as seen by Fvalue (2.66) which is less than the F-crit (3.42). It is supported by the P-value (0.09) which is greater than the alpha level (0.05). With $95 \%$ level of confidence, it can be said that the mean scores of those who did not 
receive brochures and those who received them are not significantly different from each other. Though it was declared in Table __ that those who received brochures ahead of time got the highest scores, the difference cannot be sustained to give a conclusive statement regarding the benefit of handling brochures to learners.

But for the second week, the mean scores now become significantly different from each other as seen by F-value (11.09) which is greater than the F-crit (3.42). It is supported by the P-value (0.00) which is less than then alpha level (0.05). With $95 \%$ level of confidence, it can be said that the mean scores of the three scenarios regarding handling or receiving brochures are significantly different, that is, those who received brochures before the day of discussion got the highest mean score in quizzes, and those who did not receive brochures at all got the lowest mean scores.

The same thing happened for the third week. The mean scores are significantly different from each other as seen by F-value (5.947) which is greater than the F-crit (3.422). It is supported by the P-value (0.000) which is less than then alpha level (0.05). With $95 \%$ level of confidence, it can be said that the mean scores of the three scenarios regarding handling or receiving brochures are significantly different, that is, those who received brochures before the day of discussion got the highest mean score in quizzes, and those who did not receive brochures at all got the lowest mean scores.

Looking at three weeks as a whole, the mean scores are significantly different from each other as seen by F-value (12.068) which is greater than the F-crit (3.422). It is supported by the P-value (0.000) which is less than then alpha level (0.05). With $95 \%$ level of confidence, it can be said that the mean scores of the three scenarios regarding handling or receiving brochures are significantly different, that is, those who received brochures before the day of discussion got the highest mean score in quizzes, and those who did not receive brochures at all got the lowest mean scores. The result in this study is the same with the result of the study done by Koparan (2017) in which instructional materials in Grade 7 Mathematics, High School Statistics and Method of Research were found effective in enhancing student learning.

\subsection{Benefits of Using Teacher-Made Brochures}

The table below highlights the academic inputs of the respondents with regards to the benefit of the teacher-made brochures to learners and teachers.

Table 7. Responses of Learners on the Benefits of Teacher-Made Brochures

\begin{tabular}{|c|c|}
\hline Groups & Responses \\
\hline \multirow[t]{4}{*}{ Learners } & $\begin{array}{l}\text { "We can easily understand the topic of the teacher when he discuss. We can learn the } \\
\text { lessons in advance. We can answer the teacher's question by looking in the brochure. We can be } \\
\text { more prepared when there is a discussion. It can help us to understand the formula/s well." } \\
\text { Jemarie L.Villaroza }\end{array}$ \\
\hline & $\begin{array}{l}\text { "For me the benefit of having brochures is that they will have references while } \\
\text { studying. They will easily understand what they are reading instead of just listening." } \\
\text { Avi-J Queliste }\end{array}$ \\
\hline & $\begin{array}{l}\text { "The benefits of these brochures is that it helps makes the lessons easier. The brochure } \\
\text { looks interesting so that I, as a learner, am excited with the lesson that will be discussed. Being a } \\
\text { student who is not really good in Math and it makes me understand the lesson faster." } \\
\text { Hazel M.Cortez }\end{array}$ \\
\hline & $\begin{array}{l}\text { "For me, the benefit of using teacher-made brochures is that it makes learners have a } \\
\text { better understanding of the lesson. I can easily take a look back to the past lesson. And the } \\
\text { content of the brochure is really interesting. It also made me understand the lessons. } \\
\text { Glendell Faye Pita }\end{array}$ \\
\hline
\end{tabular}


"It helps because students understand the teacher's teaching right away. Without it, you cannot follow what the teacher is discussing. You won't also remember important concepts because people don't always remember everything, especially in Math."

Mecka Ella Flores

"The benefits of the use of teacher-made brochures to learners are these. First, it is so easy for us to understand and learn because it contains all the information about the topic. Second, it is so fun because it has logic/trivia questions, inspirational quote, and a song. And third, it is so nice and good because besides the song and logic questions, it is easy to carry."

Lyca Castillo

"The benefit of the use of teacher-made brochures to learners is that, learners will have their reviewer or guidelines to the topic that their teacher will teach. Also, the learners can easily understand the topic because they can read it in advance so they can prepare if they will have a quiz."

Patricia Ramos

"The benefit of the use of teacher-made brochures is that it can be a guide to the learners to easily study his/her lesson in that short but great brochures. It can be a good lesson plan for students because it can encourage them to study more and gain more knowledge, and they can have advanced reading."

Jaimie Rivera

"We can study our lessons in advance. I understand our lessons easily. The teachermade brochures in Gen-Math and Stat made our lessons easier. And because of that brochures, we know how to solve the problem step by step."

$$
\text { Jaynalene Panaglima }
$$

"As a student, the benefit of the use of teacher-made brochure to learners like me is that we can easily understand the topic and we can read in advance. We can go back to the lesson whenever we missed something from the lecture. We can also use these brochures in our future lessons/studies."

Josette Jacob

"Having brochure when studying, like in the subject Statistics and Probability, helps us a lot. It makes us understand the lesson more. Also, we can use these brochures for future studies."

Reneth Montiero

"By the use of teacher-made brochures, the students will be able to learn the lesson properly because they have something on hand while the teacher is discussing. They can follow all the lessons that the teacher is sharing. It will also be useful for all Math teachers because in creating teacher-made brochures, they will know which lessons the students are not able to understand properly, and they will know the students who cannot follow the lesson."

Justine Ladra

"Students nowadays, we can say, are some kind of lazy, in terms of writing lectures and lessons. Teacher-made brochures are very helpful because students and teachers don't need to write lectures in their notebooks because it is already provided. All the teacher need to do is to take care of the brochures for future use." 
"Learners can have an advance reading to the topic that the teacher will discuss. Also, the learners can go back to the topic and re-read it if they can't fully analyse how to do/solve some problem. The teacher-made brochure will help learners not to have a hard time in studying Math."

Kristine Jewel R. Colipapa

"The benefit of the use of teacher-made brochures to learners is that through them, students can give the best way of studying the subject. Students can have the ability to easily understand all the topics being discussed in the classroom. Through the brochures, students who are lazy to study will be motivated to study."

Grace Angela Guisando

"The benefits of using teacher-made brochures to learners is that they can go back to the previous lesson they have already studied, they can study the next lesson, they can understand the lesson better, and the class becomes more enjoyable place for active students. It also helps the teacher in teaching the students properly."

Romnick R. Serrano

"If the teacher gives brochures to learners, the learners will be able to follow what the teacher is saying, and instead of writing a lecture, the learners just need to listen to the teacher. If there are topics that learners forgot, the learners will be able to look back to the brochures so that they can know what they forgot. And looking back is not time consuming because the brochure is concise."

John Kenneth Lucero

"The benefit of the use of teacher-made brochures to learners is that it can help the learner to have an advanced reading. It clearly shows us, the learners, that these brochures are very helpful to us to be knowledgeable, to be grateful in having a guide, and to have a good academic performance."

Mary Antonette Pandanan

"Teacher-made brochures make lessons in Gen-Math and Stat easier. It can help students to gain more knowledge. It has guidelines for learners. These brochures may not be so long, but if you read it, it is full of relevant information about a certain topic. It is also good because these brochures are not so complicated."

Jannah Mae D.Gulfan

"It made our studies in Statistics and Probability easier and more convenient. The content of each brochure is full of helpful and important information. I am very thankful that I learned a lot of knowledge from these materials without having regrets. This experience of mine and our Math teacher as well, I hope, will inspire other teachers to create brochures, too, and it will surely be of great benefit to them."

Rexibal Plata, Jr.

"We can learn the lesson in advance. We can take a look back on our past lessons. It can improve our comprehension. It provides examples so that we can understand it better. It helps us to be prepared when there is discussion."

Divine Grace Salonga 
"We can take a look at our past lesson. We can easily understand the lesson. We can learn the lesson in advance. It can help us learn more about the lesson. It can help improve our skill in analysing."

Andrea R. Tuico

"The benefit of the use of teacher-made brochures to us is that we can easily understand the lesson to be taught. It can also help us to make an overview to the upcoming lessons. It is very useful for us students because we can take a look back to the past lessons."

Cris Lian Osuna

"Brochures help me as a learner to easily understand the topic or the lesson that is given. Because of brochures, confusion is lessen and it serve as the lecture material so we can answer in the discussion easily and it save time because there would be less taking of notes.'

Tom Russel dela Cruz

"It helps to easily understand the topic and the lesson. It saves time on the part of the learner because we are not anymore taking down notes during the discussion and help to recall the past lesson that the teacher has discussed."

Christopher Bingco

"Brochures serve as a teacher's guide for the subject matter of the day. It can also be used by the teacher as activity of the student. Topics will be easier to explain on the part of the teacher if the students are handle instructional materials."

Justina D. Coronado, TIII

"I used the teacher-made brochures when I am on the meeting or on leave. The students will be very busy answering the activities in the brochure even when the teacher is not around. I also used these brochures to students that need modular approach because it also contains the lectures or summary of the lesson that they need in answering the activities."

Princess P. Sese, TI

"It enhances our teaching with simple illustrations that appeal to our learners and teach important points. It is just little but explains big concepts, therefore it serves as concise material that explains difficult things. Teacher-made brochures also serves as visual aids to make important points on instruction more vivid since pictures, diagrams, maps, time lines or other visual aids highlight important points."

Sheila C. Mallari, HT I

"Teacher-made brochures were made for its Simplicity, Mastery, Artistically, Reliability and Tactically for the learners to be SMART and they will adopt the lesson easily."

Yhezyl J. Condino, MT I

"The benefits of the use of teacher-made brochures to Math teachers is that it is an easy picked-up lesson to those teachers that will take over for an absent teacher, if brochures are prepared to be used again. It is also a great substitute for the lack of learning materials, and the teachers in making the brochures, they can easily adjust the difficulty of their lesson based on the capability of their students." 
Based from the responses, the following benefits of the teacher-made brochures to learners and to math teachers are the following:

For learners

1. Facility in taking down lecture notes, creating focused attention on teaching-and-learning process

2. Preparation for classroom discussion

3. Easy comprehension of the lesson because of concise information and direct to the point examples that go with the learners' pace

4. Motivation for learning because of logic questions, trivia, math songs presented, and reflection at the end of the brochures

5. Material for enhancement of skill

6. Serve as review material

7. Increased academic performance

For Math teachers

1. Facility on teaching because of teacher readiness and focused learners

2. Smooth classroom discussion because of lecture adaptation to interest and capability of learners

3. Reduction of stress because of learners' active participation

4. Clarity of lecture producing teacher fulfillment

5. Contingency material for teacher's unavailability

\section{Conclusion, Recommendation and Reflection}

This chapter highlights the answer to the inferential question given at the beginning of the study, lines-up recommendations to target persons, and leaves a reflection coming out of the researcher's observation and learning about the present study being undertaken.

\subsection{Conclusion}

Answering the issue about the significant difference of learners' mean scores on quizzes under three scenarios (not receiving brochures, receiving brochures on the day of the discussion, and receiving brochures beforehand), it was found out that handling brochures to learners before the day of the discussion results into significantly high scores in quizzes compared to not giving them brochures or giving them the brochures on the day of the discussion.

\subsection{Recommendation}

Based from the results obtained in the conduct of this study, the following recommendations are given here:

1. Math teachers and coordinators - Developing instructional materials like teacher-made brochures should be the math teachers guiding principle in delivering knowledge to learners. Nothing can equal an effective teacher when he or she gets inside the classroom and deliver the lesson well with confidence and readiness. Math coordinators should see to it that teachers are in a habit of developing personalized IM's that makes teaching easy and productive.

2. School head and education program specialists - Classroom monitoring and supervision should include checking of IM's that the teachers are using. School heads should encourage teachers to produce their own concise IM's that they can always bring, so no matter what emergency duty or task is given to them, the learners can continue on their pace of learning. Education Program Specialist should do the same in conducting field technical assistance, that is, inquiring of IM's that the teachers are using.

3. Future researchers - Looking into the benefit of IM's like brochures to the academic performance in other subject areas would be a fulfilling endeavor. Through that kind of extension research, other 
disciplines can be observed if they also need reading materials that the learners can read before coming to class.

\subsection{Reflection}

"To teach or not to teach." That can be a guiding principle to all teachers, whether in public or private institution. If teachers want to be an effective one, then he needs to evolve into being a book or materials fanatic into an explorer of his own invention that would suit the learners' needs. The call to produce mighty workforce for our nation's future rings to call of time because education is a powerful weapon to eradicate ignorance and poverty. The artistry in a teacher, combined with his knowledge of methods of teaching would entail for him sure success in leading learners towards better academic output. Teachers are not called to be stagnant. They are called to soar high \& offer to God worthy fruits of developed young minds.

\section{References}

Abimbade, C.T. (2004). Effective primary school science teaching, meaning, scope and strategies in T.O oyetunde, Y.A, Mallam and G.A and Zagi (ed). The practice. of teaching, perspective and strategiesPP 176-186. Jos LECAPE publishers.

Adipo, J. A. (2015). IMPACT OF INSTRUCTIONAL MATERIALS ON ACADEMIC ACHIEVEMENT IN MATHEMATICS IN PUBLIC PRIMARY SCHOOLS IN SIAYA COUNTY, KENYA. A Research Project Submitted to the University of Nairobi in Partial Fulfilment of the Requirements for the Masters of Education Degree (M.Ed) in Measurement and Evaluation.

Aduwa-Ogiegbaen S.O et al. (2005). Instructional Communication and Technology in higher education badan. Stirling Hordon Publishers(Nig)Ltd.

Bolick, C. Berson, M. Couts, C. \& Heinecke, W. (2003). Technology applications in social studies teacher education: A survey of social studies methods faculty, contemporary issues in technology and teacher education; 3(3).

Doreen, D. Et Al (2007). Using resources to Support Mathematical thinking in

Primary and Early Years, Learning Matters Ltd.

Egbu, N. C. (2012). Approach To Teaching Methodologies. Abakaliki: Bolton

Publishers Ltd

Ikwuas, O.A, Onwidiket, Y. (2006). Mathematics Phobia; Diagnosis and Prescription. First Annual Lecture: National Mathematics Centre, Abuja.

Koparan, T. (2017). Analysis of Teaching Materials Developed by Prospective Mathematics Teachers and Their Views on Materials Development. Mathematics Education Department, Ereğli Faculty of Education, Bülent Ecevit University, Zonguldak, Turkey

Montgomery, D.C (1997). Design And Analysis of Experiments (4th Edition 0 New York :John Wiley \&Sons.

Oriji, E. N (2012).Need For Using Instructional Materials In Junior Secondary Project Ebonyi State College Of Education IKWO.

Schools In Afikpo North. Unpublished NCE

Ogbondah, L. (2008). An Appraisal of Instructional Materials Used to Educate Nigeria. International Journal of Scientific Research in Education. Vol. 1(1), 13-25

Onasanya, et Al (2008).Education Performance and Assessment of Teachers' competence In Instructional Media Technologies In Junior Secondary Schools In Kwara Estate. In: Education Reforms In Nigeria. Past, Present and Future. Lawal.A.R (EDS) Stirling. Horden Publishers Ltd, Lagos, pp 259-272.

Prado, et. al. (2015). Effectiveness of Instructional Materials in High School Mathematics, Statistics and Methods of Research on Students' Performance. Professional Education Department. Central Mindanao University. The Philippine Journal for Graduate Education. Volume 1, Issue 1, February 2015

Tahir, G. (2002). Educating Disadvantaged Groups: The Case of Nomads in Nigeria, and Instruction (WCCI), Nigeria Chapter, 3(2), 135-147

Journal of the World Council for Curriculum 